
\title{
BResarch Soute \\ The influence of various smoking statuses on the resting heart rate in a physical examination population with high-normal blood pressure
}

wenyu chen ( $D$ 1984423@163.com )

Jiaxing University

\section{Zhixian Fang}

Jiaxing University

Yufeng Xu

First Hospital of Jiaxing

\section{Research}

Keywords: Smoking, high-normal blood pressure, resting heart rate, blood lipids, hypertension

Posted Date: February 6th, 2020

DOI: https://doi.org/10.21203/rs.2.22784/v1

License: (c) (i) This work is licensed under a Creative Commons Attribution 4.0 International License.

Read Full License 


\section{Abstract}

\section{Background}

The exact relation between smoking statuses and hypertension in the population with high-normal BP is poorly understood. Objective To investigate the influence of various smoking statuses (active smoking, passive smoking, and non-smoking) on the resting heart rate of the population with high-normal blood pressure.

Methods

This was a cross-sectional study of patients undergoing physical examination at three Chinese hospitals between January 2018 and December 2019, and who conformed with the criteria of high-normal BP. The subjects were classified into the non-smoking, active smoking and passive smoking groups. The resting heart rate (RHR) and blood pressure (BP) were measured. High-density lipoprotein cholesterol (HDL-C), low-density lipoprotein (LDL-C), triglycerides (TG), total cholesterol (TC), and fasting blood glucose (FBG) were measured.

Results

TG, TC, and FBG were significantly higher in the active smoking group than in the two other groups (all $P<0.05)$. HDL-C levels were lower in the active smoking group than in the two other groups $(P<0.05)$. There were significant differences in RHR among the three groups (active: $76.0 \pm 10.1$ vs. passive: $72.6 \pm 5.8$ vs. non-smoking: $69.4 \pm 4.4 \mathrm{bpm}, \mathrm{P}<0.01$ ). Active smoking (odds ratio $(\mathrm{OR})=5.13, \mathrm{P}<0.05), \mathrm{SBP}$ $(\mathrm{OR}=0.70, \mathrm{P}<0.05), \mathrm{HDL}-\mathrm{C}(\mathrm{OR}=0.58, \mathrm{P}<0.05)$, and passive smoking $(\mathrm{OR}=3.57, \mathrm{P}<0.05)$ were independently associated with increased RHR.

\section{Conclusion}

RHR was higher in subjects with high-normal BP and in the passive and active smoking groups.

Strengthening smoking cessation education and avoiding exposure secondary smoke could be beneficial to control the population with high-normal BP.

\section{Background}

Hypertension is a common cardiovascular disease characterized by sustained elevated blood pressure (BP) [1]. Hypertension is one of the main controllable risk factors of cardiovascular events [2]. In recent years, the prevalence of hypertension has been increasing every year. In the United States, $41 \%$ of people of 35-70 years of age have hypertension [3]. In China, $36.7 \%$ and $56.5 \%$ of people aged $45-64$ years and $\geq 65$ years, respectively, have hypertension [4].

The need for early prevention of hypertension has achieved a global consensus [2]. In order to emphasize the importance of the primary prevention of hypertension, the concept of pre-hypertension had been 
proposed in The Seventh Report of the Joint National Committee on Prevention, Detection, Evaluation, and Treatment of High Blood Pressure (JNC7) in 2003 [2]. The purpose of the pre-hypertension concept aims to screen and prevent hypertension in the population with high-normal BP. Although the concept of pre-hypertension has not been completely accepted in China, the Chinese guidelines for prevention and treatment of hypertension has also raised the concept of high-normal blood pressure [5], and the range of high-normal BP is similar to that raised by JNC7 [2].

It is currently considered that lifestyle changes could be one of the most effective interventions for people with high-normal BP. Smoking is regarded as an adverse lifestyle habit by the World Health Organization (WHO) and it is significantly related to hypertension [6], but the exact relation between smoking statuses and hypertension in the population with high-normal BP is poorly understood.

Therefore, this study examined the resting hear rate (RHR), blood lipids, blood glucose, and BP of 210 patients with high-normal BP and various smoking statuses in order to investigate the influence of the smoking status on cardiovascular parameters in the population with high-normal BP.

\section{Subjects And Methods}

\section{Study design and subjects}

This was a cross-sectional study of individuals undergoing physical examination at the First Hospital of Jiaxing, the Fifth Hospital of Yuhang District in Hangzhou, and Zhejiang Hospital between January 2018 and December 2019, and who conformed with the criteria of high-normal BP [5,2]. The systolic BP (SBP) had to be 120-139 mmHg and/or the diastolic (DBP) had to be $80-89 \mathrm{mmHg}$. This study was approved by the ethics committee of all three hospitals. The subjects provided a written informed consent.

The inclusion criteria were: 1) individuals confirmed with high-normal BP; 2) no medical history of hypertension; 3) no antihypertensive drugs; and 4) complete dataset. The exclusion criteria were: 1) history of cardiovascular disease; 2 ) history of thyroid disease; or 3 ) medical history of malignant tumor.

\section{Methods}

A home-made questionnaire was administered and included the smoking status, alcohol history, physical exercise, sleeping time, educational level, personal disease history, family disease history, and history of drug therapy. Non-smoker was defined as never having smoked or not currently smoking and having smoked $<100$ cigarettes for lifetime (passive smoking was not included). Passive smoker was defined as being exposed to exhaled smoke for at least 15 min per day every week. Smoker was defined as currently smoking. All questionnaires were completed by the subjects and checked by the trained medical personnel.

RHR, height, and weight were measured. The body mass index (BMI) was calculated as weight $(\mathrm{kg})$ divided by squared height $\left(\mathrm{m}^{2}\right)$. An automatic biochemical analyzer was used to routinely measure the 
fasting blood glucose (FBG), triglycerides (TG), total cholesterol (TC), high-density lipoprotein cholesterol $(\mathrm{HDL}-\mathrm{C})$, and low-density lipoprotein cholesterol (LDL-C) levels.

After the subjects had rested for about 5 min in a quiet environment, RHR was measured using an electrocardiogram system in order to record the standard 12-lead electrocardiogram in the supine position. The five consecutive ORS waves of II lead were selected and the RR intervals were measured. The mean RR interval was recorded as the RHR. After the subject had rested for about 10 min in a quiet environment, right brachial SBP and DBP were measured using a standard desktop mercury sphygmomanometer. The first Korotkoff's sound was regarded as the SBP, and the fifth Korotkoff's sound was regarded as DBP. The measurements were repeated three times and the mean value was calculated.

\section{Statistical analysis}

Continuous variables were presented as the mean \pm standard deviation and analyzed using one-way analysis of variance (ANOVA) with the least significant difference (LSD) post-hoc test. Categorical data were presented as frequencies and analyzed using the chi-square test or Fisher's exact test, as appropriate. The potential factors independently associated with RHR were analyzed by multivariate logistic regression analysis. SPSS 17.0 (IBM, Armonk, NY, USA) was used for statistical analyses. Twosided P-values $<0.05$ were considered statistically significant.

\section{Results}

\section{Characteristics of the subjects}

A total of 210 subjects with high-normal BP were enrolled in the present study. The baseline characteristics of the subjects were shown in Table 1. There were 140 males and 70 females, aged $55.6 \pm$ 8.5 (range, 45 to 75 ) years. The subjects were classified into three groups according to the smoking status. There were 78 subjects in the non-smoking ( 47 males and 31 females), 68 subjects in the active smoking group (53 males and 15 females), for a smoking rate of $32.4 \%$, and there were 74 subjects in the passive smoking group (40 males and 24 females). There were no significant differences in age, gender, $\mathrm{BMI}$, alcohol consumption, physical exercise, sleeping time, and family history of hypertension among the three groups.

\section{Characteristics of the subjects}

A total of 210 subjects with high-normal BP were enrolled in the present study. The baseline characteristics of the subjects were shown in Table 1. There were 140 males and 70 females, aged $55.6 \pm 8.5$ (range, 45 to 75 ) years. The subjects were classified into three groups according to the smoking status. There were 78 subjects in the non-smoking ( 47 males and 31 females), 68 subjects in the active smoking group (53 males and 15 females), for a smoking rate of $32.4 \%$, and there were 74 subjects in the passive smoking group (40 males and 24 females). There were no significant differences in age, gender, $\mathrm{BMI}$, alcohol consumption, physical exercise, sleeping time, and family history of hypertension among the three groups. 


\section{Blood lipids}

Blood lipids were compared among the smoking status groups. TG, TC, and FBG were significantly higher in the active smoking group than in the two other groups (all $\mathrm{P}<0.05$ ). HDL-C levels were lower in the active smoking group than in the two other groups $(P<0.05)$. Compared with the non-smoking group, the TC, HDL-C, and FBG levels of the passive smoking group showed no significant difference (all $P>0.05$ ) (Table 1).

\section{Blood pressure and heart rate according to smoking status}

BP and RHR were compared among the smoking status groups. SBP, DBP, and RHR in the active smoking group were significantly higher than that of the two other groups (all $\mathrm{P}<0.05$ ). There were no differences in SBP and DBP between the non-smoking and passive smoking groups (all P>0.05), but RHR of the passive smoking group was higher than that of the non-smoking group $(P<0.05)($ Table 1$)$. 
Table 1

Characteristics of the subjects according to the smoking status

\begin{tabular}{|c|c|c|c|c|c|}
\hline & & $\begin{array}{l}\text { Active } \\
\text { smoking }\end{array}$ & $\begin{array}{l}\text { Passive } \\
\text { smoking }\end{array}$ & $\begin{array}{l}\text { Non- } \\
\text { smoking }\end{array}$ & $\mathbf{P}$ \\
\hline $\mathrm{n}$ & & 68 & 64 & 78 & \\
\hline Age (years old) & & $55.2 \pm 8.6$ & $56.2 \pm 9.1$ & $57.2 \pm 8.1$ & $\begin{array}{l}> \\
0.05\end{array}$ \\
\hline \multirow[t]{2}{*}{ Gender } & Male & $53(77.9)$ & $40(62.5)$ & $47(60.3)$ & \multirow{2}{*}{$\begin{array}{l}> \\
0.05\end{array}$} \\
\hline & Female & $15(22.1)$ & $24(37.5)$ & $31(39.7)$ & \\
\hline \multirow[t]{2}{*}{ Alcohol consumption } & Yes & $25(36.8)$ & 20 (31.3) & $28(35.9)$ & \multirow{2}{*}{$\begin{array}{l}> \\
0.05\end{array}$} \\
\hline & No & $43(73.2)$ & 44 (78.7) & $50(64.1)$ & \\
\hline \multirow[t]{2}{*}{ Physical exercise } & Yes & $25(36.8)$ & $31(48.4)$ & $27(34.6)$ & \multirow{2}{*}{$\begin{array}{l}> \\
0.05\end{array}$} \\
\hline & No & $43(73.2)$ & $33(51.6)$ & $51(65.4)$ & \\
\hline Sleeping time $(\mathrm{h})$ & & $6.7 \pm 1.1$ & $7.0 \pm 1.0$ & $6.7 \pm 1.0$ & $\begin{array}{l}> \\
0.05\end{array}$ \\
\hline \multirow{2}{*}{$\begin{array}{l}\text { Family history of } \\
\text { hypertension }\end{array}$} & Yes & $12(17.7)$ & $9(14.1)$ & 15 (19.2) & \multirow{2}{*}{$\begin{array}{l}> \\
0.05\end{array}$} \\
\hline & No & $56(82.3)$ & $55(85.9)$ & $63(80.8)$ & \\
\hline BMI (kg/m2) & & $23.2 \pm 2.9$ & $23.6 \pm 3.1$ & $23.0 \pm 2.9$ & 0.97 \\
\hline TG (mmol/L) & & $1.5 \pm 0.3 \mathrm{ab}$ & $1.4 \pm 0.3^{a}$ & $1.3 \pm 0.2$ & $\begin{array}{l}< \\
0.01\end{array}$ \\
\hline $\mathrm{TC}(\mathrm{mmol} / \mathrm{L})$ & & $4.4 \pm 1.1^{\mathrm{ab}}$ & $3.8 \pm 0.9$ & $3.5 \pm 0.8$ & $\begin{array}{l}<.01 \\
0.01\end{array}$ \\
\hline LDL-C (mmol/L) & & $2.5 \pm 0.9 \mathrm{ab}$ & $2.5 \pm 0.8^{a}$ & $2.1 \pm 0.8$ & $\begin{array}{l}< \\
0.01\end{array}$ \\
\hline HDL-C (mmol/L) & & $1.5 \pm 0.3^{a b}$ & $1.9 \pm 0.7$ & $2.0 \pm 0.4$ & 0.26 \\
\hline FBG (mmol/L) & & $5.4 \pm 1.1^{a b}$ & $4.6 \pm 1.2$ & $4.5 \pm 1.1$ & $\begin{array}{l}< \\
0.01\end{array}$ \\
\hline
\end{tabular}

BMI: body mass index; TG: triglycerides; TC: total cholesterol; LDL-C: low-density lipoprotein cholesterol; HDL-C: high-density lipoprotein cholesterol; FBG: fasting blood glucose; SBP: systolic blood pressure; DBP: diastolic blood pressure; RHR: resting heart rate.

Data were expressed as mean \pm standard deviation or as $\mathrm{n}(\%)$, as appropriate.

a $\mathrm{P}<0.05$ vs. the non-smoking group

${ }^{b} \mathrm{P}<0.05$ vs. the passive smoking group 


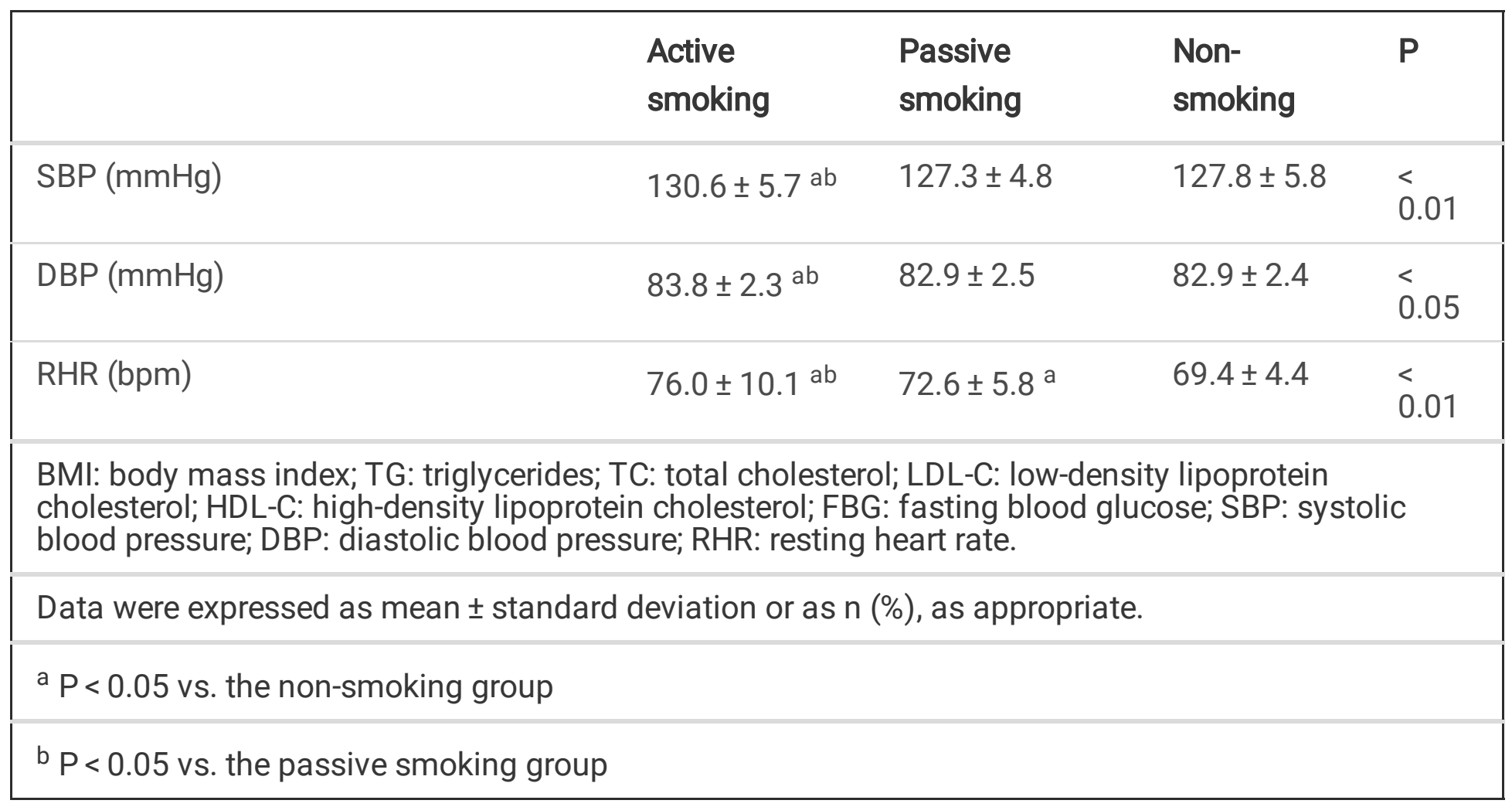

\section{Multivariate Analysis}

$\mathrm{RHR} \geq 75 \mathrm{bpm}$ was considered as increased heart rate and its association with clinical factors was examined by multivariate analysis. Smoking status, age, gender, BMI, SBP, DBP, TG, TC, HDL-C, and LDL-C were considered as the independent variables. The results showed that in a physical examination population with high-normal BP, active smoking, SBP, HDL-C, and passive smoking were independently associated with increased RHR. Of them, active smoking, passive smoking, and SBP were positively associated with RHR, while HDL-C was negatively associated (Table 2). 
Table 2

Multivariate analysis of factors associated with RHR

\begin{tabular}{|llllll|}
\hline Independent variables & $\boldsymbol{\beta}$ & Standard error & Wals & OR & P \\
\hline Active smoking & 1.64 & 0.40 & 17.07 & 5.13 & $<0.05$ \\
\hline Passive smoking & 1.27 & 0.37 & 11.79 & 3.57 & $<0.05$ \\
Gender & 0.43 & 0.31 & 1.89 & 1.53 & $>0.05$ \\
\hline BMI & -0.37 & 0.20 & 3.38 & 0.69 & $>0.05$ \\
SBP & 0.36 & 0.30 & 1.47 & 0.70 & $<0.05$ \\
DBP & -0.56 & 0.33 & 2.92 & 0.57 & $>0.05$ \\
\hline TG & 0.31 & 0.29 & 1.15 & 1.37 & $>0.05$ \\
\hline TC & 0.20 & 0.29 & 0.46 & 1.22 & $>0.05$ \\
\hline LDL-C & -0.48 & 0.31 & 2.42 & 0.62 & $>0.05$ \\
\hline HDL-C & -0.55 & 0.29 & 3.46 & 0.58 & $<0.05$ \\
\hline $\begin{array}{l}\text { BMI: body mass index; TG: triglycerides; TC: total cholesterol; LDL-C: low-density lipoprotein } \\
\text { cholesterol; HDL-C: high-density lipoprotein cholesterol; FBG: fasting blood glucose; SBP: systolic } \\
\text { blood pressure; DBP: diastolic blood pressure; RHR: resting heart rate. }\end{array}$ & & \\
\hline
\end{tabular}

\section{Discussion}

The exact relation between smoking statuses and hypertension in the population with high-normal BP is poorly understood. Therefore, this study aimed to investigate the influence of various smoking statuses (active smoking, passive smoking, and non-smoking) on the resting heart rate of the population with high-normal blood pressure. Results strongly suggest that RHR was higher in subjects with high-normal $\mathrm{BP}$ and in the passive and active smoking groups. Strengthening smoking cessation education and avoiding exposure secondary smoke could be beneficial to control the population with high-normal BP.

China has the largest number of smokers in the world. In 2010, the National Adult Tobacco Survey by the China Disease Prevention and Control Center indicated that the overall smoking rate was $33.5 \%$ in the population aged $>15$ years old in China $[7,8]$. Of them, the men accounted for $62.8 \%$; in addition, $72.4 \%$ of the non-smokers were exposed to secondary smoke [7, 8]. Many studies confirmed that smoking is an important risk factor for hypertension [9].

In China, the occurrence rate of high-normal BP is relatively higher in adults, which could reach up to $37 \%$ [10-12]. People with high-normal BP are at high-risk to develop hypertension [2]. In clinical practice, the ratio of patients developing hypertension from high-normal BP over a 2-year period could reach $32.5 \%$ [13]. In addition, these patients are at high risk of metabolic diseases such as diabetes [14]. 
RHR indicates the heart rate in the conscious and resting status. Recently, it has been shown that RHR was closely related to cardiovascular diseases, especially hypertension [15-17]. Indeed, there is a strong relationship between elevated RHR and incident cardiovascular diseases, both in men and women [17]. In the early stage of primary hypertension, the range of RHR may increase by $10-15 \%$ [18]. Increased RHR in hypertensive patients could induce injuries to blood vessels, heart, kidney, and endocrine system [19, 20]. Therefore, increased RHR is not only an independent risk factor for hypertension development from highnormal BP, but also a potential risk factor for cardiovascular events in hypertensive patients. Increased RHR is a strong predictor of death in patients with hypertension [20].

It has been observed that the nicotine in cigarettes could change the excitability of the cardiac sympathetic and vagus nerves, and further significantly decrease the heart rate variability (HRV) of smokers [21]. Meanwhile, nicotine could also increase heart rate and BP. The results of the present study suggested that SBP, DBP, and RHR of active smokers with high-normal BP were significantly higher than that of passive smokers and non-smokers. The results indicated that both active and passive smokers displayed RHR acceleration. These results could be consistent with the fact that nicotine intake of passive smokers is smaller than that of active smokers.

In addition, this study also found that the blood lipid levels of subjects with pre-hypertension could be influenced by the smoking status. Indeed, LDL-C and TG levels of active and passive smokers were higher than that of non-smokers. A number of studies indicated that the inhaled substances of tobacco combustion could affect lipid metabolism, i.e. stimulate LDL-C synthesis, inhibit HDL-C synthesis, and increase TC and TG [22-24]. Therefore, long-term smoking could result in the increase of TC, TG, and LDL-C levels, and decline of HDL-C level. In addition, the multivariate analysis showed that HDL-C was negatively and independently associated with RHR. However, the mechanism of RHR influenced by blood lipids still needs to be further studied.

The present study is not without limitation. The sample size was limited and from only three hospitals. Only a limited number of factors were analyzed. Low-grade inflammatory state is well-known to be associated with smoking [25] and it could be interesting to analyze inflammatory factors in relation to RHR. Finally, as a cross-sectional study, no cause-to-effect relationship could be established.

\section{Conclusion}

RHR was higher in subjects with high-normal BP and in the passive and active smoking groups.

Strengthening smoking cessation education and avoiding exposure secondary smoke could be beneficial to control the population with high-normal BP.

\section{Declarations}

Acknowledgements 
The study investigators would like to acknowledge Xiaoping Zhang for his contribution to the development of the study protocol.

\section{Author contributions}

WENYU CHEN conceptualized, drafted, and led the writing of the manuscript. ZHIXIAN FANG provided overall conceptual guidance for the study and Yufeng Xu closely worked withChanglin Zhai to develop the article. All authors have contributed to the writing and reviewed and approved the final manuscript.

\section{Competing interests}

All authors declare that they have no competing interests.

\section{Ethics approval and consent to participate}

The research was reviewed and approved by the the First Affiliated Hospital of Jiaxing University Ethics committee. Written informed consent was obtained from all participants.

\section{Consent for publication}

All authors agree to publish this work.

\section{Availability of data and materials}

The datasets are available under reasonable request.

\section{Funding}

This study was supported by the key development projects for Respiratory departments of Jiaxing (2019zc-04).

\section{References}

1. James PA, Oparil S, Carter BL, Cushman WC, Dennison-Himmelfarb C, Handler J, Lackland DT, LeFevre ML, MacKenzie TD, Ogedegbe O, Smith SC, Jr., Svetkey LP, Taler SJ, Townsend RR, Wright JT, Jr., Narva AS, Ortiz E (2014) 2014 evidence-based guideline for the management of high blood 
pressure in adults: report from the panel members appointed to the Eighth Joint National Committee (JNC 8). Jama 311 (5):507-520. doi:10.1001/jama.2013.284427

2. Chobanian AV, Bakris GL, Black HR, Cushman WC, Green LA, Izzo JL, Jr., Jones DW, Materson BJ, Oparil S, Wright JT, Jr., Roccella EJ, National Heart L, Blood Institute Joint National Committee on Prevention DE, Treatment of High Blood P, National High Blood Pressure Education Program Coordinating C (2003) The Seventh Report of the Joint National Committee on Prevention, Detection, Evaluation, and Treatment of High Blood Pressure: the JNC 7 report. Jama 289 (19):2560-2572. doi:10.1001/jama.289.19.2560

3. Chow CK, Teo KK, Rangarajan S, Islam S, Gupta R, Avezum A, Bahonar A, Chifamba J, Dagenais G, Diaz R, Kazmi K, Lanas F, Wei L, Lopez-Jaramillo P, Fanghong L, Ismail NH, Puoane T, Rosengren A, Szuba A, Temizhan A, Wielgosz A, Yusuf R, Yusufali A, McKee M, Liu L, Mony P, Yusuf S, investigators PS (2013) Prevalence, awareness, treatment, and control of hypertension in rural and urban communities in high-, middle-, and low-income countries. Jama 310 (9):959-968. doi:10.1001/jama.2013.184182

4. Gao Y, Chen G, Tian H, Lin L, Lu J, Weng J, Jia W, Ji L, Xiao J, Zhou Z, Ran X, Ren Y, Chen T, Yang W, China National D, Metabolic Disorders Study G (2013) Prevalence of hypertension in china: a crosssectional study. PloS one 8 (6):e65938. doi:10.1371/journal.pone.0065938

5. Chinese guidelines for hypertension prevention and treatment Revision Committee. Chinese guidelines for hypertension prevention and treatment (revised edition 2005) (2006). People's Medical Publishing House, Beijing

6. Whitworth JA, World Health Organization ISoHWG (2003) 2003 World Health Organization (WHO)/International Society of Hypertension (ISH) statement on management of hypertension. Journal of hypertension 21 (11):1983-1992. doi:10.1097/01.hjh.0000084751.37215.d2

7. Zhang J, Ou JX, Bai CX (2011) Tobacco smoking in China: prevalence, disease burden, challenges and future strategies. Respirology 16 (8):1165-1172. doi:10.1111/j.1440-1843.2011.02062.x

8. Li Q, Hsia J, Yang G (2011) Prevalence of smoking in China in 2010. The New England journal of medicine 364 (25):2469-2470. doi:10.1056/NEJMc1102459

9. Eguchi K, Pickering TG, Hoshide S, Ishikawa J, Ishikawa S, Schwartz JE, Shimada K, Kario K (2008) Ambulatory blood pressure is a better marker than clinic blood pressure in predicting cardiovascular events in patients with/without type 2 diabetes. American journal of hypertension 21 (4):443-450. doi:10.1038/ajh.2008.4

10. Xu T, Zhu G, Liu J, Han S (2015) Gender-specific prevalence and associated risk factors of high normal blood pressure and hypertension among multi-ethnic Chinese adolescents aged 8-18 years old. Blood pressure 24 (3):189-195. doi:10.3109/08037051.2015.1025474

11. Xu G, Liu J, Liu S, Zhou H, Orekoya O, Liu J, Li Y, Tang J, Zhou C, Huang J (2015) The Expanding Burden of Elevated Blood Pressure in China: Evidence From Jiangxi Province, 2007-2010. Medicine 94 (39):e1623. doi:10.1097/MD.0000000000001623 
12. Sun Z, Zheng L, Wei Y, Li J, Zhang X, Zhang X, Liu S, Xu C, Li J, Zhao F, Dong G, Hu D, Sun Y (2007) The prevalence of prehypertension and hypertension among rural adults in Liaoning province of China. Clinical cardiology 30 (4):183-187. doi:10.1002/clc.20073

13. Meisinger C, Doring A, Heier M (2008) Blood pressure and risk of type 2 diabetes mellitus in men and women from the general population: the Monitoring Trends and Determinants on Cardiovascular Diseases/Cooperative Health Research in the Region of Augsburg Cohort Study. Journal of hypertension 26 (9):1809-1815. doi:10.1097/HJH.0b013e328307c3e9

14. Gress TW, Nieto FJ, Shahar E, Wofford MR, Brancati FL (2000) Hypertension and antihypertensive therapy as risk factors for type 2 diabetes mellitus. Atherosclerosis Risk in Communities Study. The New England journal of medicine 342 (13):905-912. doi:10.1056/NEJM200003303421301

15. Kolloch R, Legler UF, Champion A, Cooper-Dehoff RM, Handberg E, Zhou Q, Pepine CJ (2008) Impact of resting heart rate on outcomes in hypertensive patients with coronary artery disease: findings from the INternational VErapamil-SR/trandolapril STudy (INVEST). European heart journal 29 (10):13271334. doi:10.1093/eurheartj/ehn123

16. Gillum RF (1988) The epidemiology of resting heart rate in a national sample of men and women: associations with hypertension, coronary heart disease, blood pressure, and other cardiovascular risk factors. American heart journal 116 (1 Pt 1):163-174

17. Cooney MT, Vartiainen E, Laatikainen T, Juolevi A, Dudina A, Graham IM (2010) Elevated resting heart rate is an independent risk factor for cardiovascular disease in healthy men and women. American heart journal 159 (4):612-619 e613. doi:10.1016/j.ahj.2009.12.029

18. Courand PY, Lantelme $P$ (2014) Significance, prognostic value and management of heart rate in hypertension. Archives of cardiovascular diseases 107 (1):48-57. doi:10.1016/j.acvd.2013.11.003

19. Beddhu S, Nigwekar SU, Ma X, Greene T (2009) Associations of resting heart rate with insulin resistance, cardiovascular events and mortality in chronic kidney disease. Nephrology, dialysis, transplantation : official publication of the European Dialysis and Transplant Association - European Renal Association 24 (8):2482-2488. doi:10.1093/ndt/gfp057

20. Paul L, Hastie CE, Li WS, Harrow C, Muir S, Connell JM, Dominiczak AF, Mclnnes GT, Padmanabhan S (2010) Resting heart rate pattern during follow-up and mortality in hypertensive patients. Hypertension 55 (2):567-574. doi:10.1161/HYPERTENSIONAHA.109.144808

21. Walker JF, Loprinzi PD, Kane CJ (2013) Do nicotine intake and acute heart rate response to smoking rank nicotine dependence the same? Sheng li xue bao : [Acta physiologica Sinica] 65 (3):319-322

22. Gepner AD, Piper ME, Johnson HM, Fiore MC, Baker TB, Stein JH (2011) Effects of smoking and smoking cessation on lipids and lipoproteins: outcomes from a randomized clinical trial. American heart journal 161 (1):145-151. doi:10.1016/j.ahj.2010.09.023

23. Meenakshisundaram R, Rajendiran C, Thirumalaikolundusubramanian P (2010) Lipid and lipoprotein profiles among middle aged male smokers: a study from southern India. Tobacco induced diseases 8:11. doi:10.1186/1617-9625-8-11 
24. Ashakumary L, Vijayammal PL (1997) Effect of nicotine on lipoprotein metabolism in rats. Lipids 32 (3):311-315

25. Lee J, Taneja V, Vassallo R (2012) Cigarette smoking and inflammation: cellular and molecular mechanisms. Journal of dental research 91 (2):142-149. doi:10.1177/0022034511421200 